\title{
PROPOSTA DE IMPLEMENTAÇÃO DE UM MERCADO COMO REFERÊNCIA PARA O DIRECIONAMENTO CRIATIVO DE UMA MARCA: ESTUDO DE CASO NA LTRG COMÉRCIO VAREJISTA DE ÓCULOS E RELÓGIOS LTDA
}

\section{ARTIGO ORIGINAL}

LIMA, Adriana Ribeiro de ${ }^{1}$, COLARES, Larissa Farias ${ }^{2}$, COSTA, Lizandra da Silva $^{3}$, ROBERTO, José Carlos Alves ${ }^{4}$, ALMEIDA, Victor da Silva ${ }^{5}$, LEITE, Ygor Geann dos Santos ${ }^{6}$

LIMA, Adriana Ribeiro de. Et al. Proposta de implementação de um mercado como referência para o direcionamento criativo de uma marca: estudo de caso na LTRG Comércio Varejista de Óculos e Relógios Ltda. Revista Científica Multidisciplinar Núcleo do Conhecimento. Ano 06, Ed. 11, Vol. 12, pp. 134-153. Novembro de 2021. ISSN: 2448-0959, Link de acesso: https://www.nucleodoconhecimento.com.br/administracao/mercado-como-referencia, DOI: $\quad 10.32749 /$ nucleodoconhecimento.com.br/administracao/mercado-comoreferencia

\section{RESUMO}

O artigo apresenta um estudo de caso na empresa LTRG Comércio Varejista de Óculos e Relógios Ltda, que atualmente atua no ramo do comércio varejista com vendas de óculos e relógios. O estudo surgiu a partir do resultado do diagnóstico organizacional, que apontou a área de marketing como a mais crítica, principalmente

\footnotetext{
${ }^{1}$ Graduanda do curso de Administração.

${ }^{2}$ Graduando do curso de Administração.

${ }^{3}$ Graduando do curso de Administração.

${ }^{4}$ Orientador. Mestre em Engenharia de produção. Especialista Logística empresarial. Graduado em Administração com Ênfase em Marketing.

${ }^{5}$ Coorientador. Mestre em Engenharia de Processos. Pós-Graduando em Neuropsicopedagogia Institucional. Especialista em Gestão Estratégica de RH. Graduado em Administração e Pedagogia.

${ }^{6}$ Coorientador. Mestre em Ciência e Engenharia de Materiais. Especialista em Engenharia da Qualidade e Seis Sigma. Graduado em Tecnologia em Gestão da Qualidade.
}

RC: 101965

Disponível em: https://www.nucleodoconhecimento.com.br/administracao/mercadocomo-referencia 
no contexto relacionado ao baixo poder de penetração da marca em todas as faixas da população. Neste contexto, tem como questão norteadora: Como melhorar a visibilidade da marca por meio de estratégias de divulgação da empresa em todas as faixas de poder aquisitivo? O objetivo geral do estudo buscou desenvolver a visibilidade da marca por meio de ações integradas de marketing, apresentando ao mercado produtos compatíveis com todas as faixas de poder aquisitivo, com objetivo de tornar a marca reconhecida pelos consumidores, como uma marca de referência em qualidade e diversificação de produtos com preços compatíveis. A metodologia utilizada no estudo se ancorou em uma pesquisa bibliográfica e de campo, por meio de uma abordagem qualitativa. Como resultado identificou-se um direcionamento para 0 mercado com produtos adequados, abrindo novas oportunidades e perspectivas de criação e desenvolvimentos de mercados e produtos. $O$ estudo possibilitou observar que a empresa necessita se adequar às formas e tendências de divulgação dos produtos no mercado digital, que se inova constantemente. $O$ $5 \mathrm{~W} 2 \mathrm{H}$ foi a ferramenta aplicada neste estudo para analisar as áreas funcionais e programar melhorias nas divulgações com todos os meios de redes sociais e a promoção de produtos online, utilizando várias plataformas de vendas online e fazendo divulgações por meios virtuais. Por fim, o estudo atingiu seus objetivos preparando um conjunto de ações de marketing que, a partir de sua implementação, pode encontrar êxito na solução dos problemas diagnosticados e orientar a empresa no caminho dos resultados positivos, a médio e longo prazo, através de ações que proporcionarão o engajamento da marca nas diferentes formas, tornando a organização mais visível aos clientes e aumentando as demandas.

Palavras-chave: produtos, $5 \mathrm{~W} 2 \mathrm{H}$, marketing, visibilidade, divulgação.

\section{INTRODUÇÃO}

Com o avanço do mercado, a interação com o cliente mudou de forma considerável. Todas as etapas de gestão das empresas sofreram mudanças, desde a sua geração até sua disposição final, exigindo soluções práticas e eficientes no trato com o 
cliente, nas negociações de vendas e na coleta de informações para estratégias futuras de mercado.

Atualmente, percebe-se que na concorrência, a comunicação torna-se uma aliada para atuar na ampliação dos negócios das organizações, sendo importantíssimo o seu desenvolvimento contínuo no mercado em evolução.

Posto isso, Kohn e Elias (2014) apontam que o conhecimento científico é obtido através de uma expectativa do investigador advinda de alguma experiência prévia, podendo ser relacionada com a pergunta problema. Neste sentido, o trabalho teve como questionamento: como melhorar a visibilidade da marca por meio de estratégias de divulgação da empresa em todas as faixas de poder aquisitivo?

Contudo, as melhorias frente à questão apresentada foram examinadas sob a perspectiva das dificuldades da empresa LTRG Comércio Varejista de Óculos e Relógio Ltda. Logo, a melhora da amostra e do marketing da empresa foi analisada com base na ferramenta de qualidade que nos revelou problemas de: baixa divulgação da marca e a dificuldade em atender todos os públicos. Frente a esses problemas, foram realizadas correções na difusão dos produtos para alavancar as vendas, mas também para inserir melhorias na divulgação da marca da empresa, que exerce um bom atendimento de vendas e relacionamento com os clientes.

Para tanto, este estudo teve como objetivo principal estabelecer ações integradas para maior divulgação da empresa, propondo formas de se relacionar com os clientes por meios virtuais e de rápida propagação. Para isso, elaborou-se um direcionamento para o mercado, gerando tendências, focando nas modas inovadoras, abrindo novas oportunidades e perspectivas de criação do produto.

A metodologia utilizada neste estudo se ancorou em uma pesquisa bibliográfica, de campo e documental, por meio de uma abordagem qualitativa. Foi realizada uma entrevista com a gerente da empresa, onde foram feitas perguntas abertas e fechadas com o objetivo de aproximar-se da realidade investigada. Analisou-se 
ainda, planilhas e documentos da empresa, que proporcionaram maior entendimento das necessidades de melhoria no setor de marketing da empresa.

Após análise dos dados, implementou-se ações que visam a melhora da divulgação dos produtos da empresa nas diferentes redes sociais. Como resultado, percebeu-se que a empresa obteve maior engajamento da sua marca nas redes sociais e melhor feedback dos clientes, onde verificou-se um retorno dos clientes quanto a qualidade dos produtos, atendimento e divulgação da marca.

\section{FUNDAMENTAÇÃO TEÓRICA}

A fundamentação teórica é um elemento fundamental para a realização de qualquer pesquisa. Trata-se da parte, onde as informações relacionadas ao assunto investigado são apresentadas com base em livros, artigos, documentos, entre outros. Posto isso, esta deve compor-se por informações de fontes verdadeiras e requintes de informações qualitativas e quantitativas.

Para essa parte do trabalho, são necessárias bases sólidas para comprovar fundamentos e teorias, não apenas em artigos científicos, mas também em projetos a serem implementados na prática, que necessitarão de exatidão de dados e processos objetivos.

Neste sentido, este estudo buscou elencar os diferentes textos já publicados sobre o tema, para construir uma análise sobre a realidade vivenciada pela empresa estudada neste trabalho.

\subsection{CONCEITO DE MARKETING}

O Marketing conceitua-se em uma ciência com a finalidade de criar, explorar e agregar valor, para atender as necessidades do público, gerando lucro. Tendo como principal objetivo identificar e gerar valores, para fazer uma ligação com seus possíveis compradores. 
Esse modelo de gerenciamento não apenas avalia o mercado, o seu comportamento e as necessidades dos clientes, mas também desenvolve projeções sobre futuros mercados, nichos específicos e tendências futuras, e explora as diversas situações que ocorrem, transformando as necessidades em oportunidades de crescimento de novos produtos e até mesmo mercados.

Conforme Silva (2015), o profissional de marketing estimula e desenvolve a troca com o cliente para atender ambas as partes. O Marketing age de forma bem espontânea buscando satisfazer os envolvidos, tanto ofertando como recebendo algo de valor, a fim de que haja uma troca onde todos saiam satisfeitos.

Segundo Sganzerlla (2013), o Marketing é indispensável para se obter o sucesso nos negócios, e isso pode ser confirmado através da grande quantidade bibliográfica cedida no meio acadêmico, destacando as áreas de um negócio com foco no aspecto de marketing.

\subsubsection{DIVULGAÇÃO NAS REDES SOCIAIS}

É um exercício que comunica a integração das empresas com os clientes, ou vice e versa, onde através de sites divulgam sua marca de modo abrangente e rápido.

A divulgação online também oferece segurança e comodidade para os clientes, já que não há a necessidade de sair de casa para consultar lojas e serviços e adquirir o mesmo, em razão do alcance da divulgação que é de fato bem mais abrangente do que seria de forma física.

Rocha et al. (2013) apontam que essa forma de divulgação promove maior agilidade das informações que chegam e atingem os clientes, causando grandes proporções, de maneira a influenciar os que interagem nas páginas.

Para Valle (2014), ainda que o marketing seja útil para algumas pessoas, o mesmo pode trazer um certo estresse para outras, devido à quantidade de propagandas $e$ anúncios que chegam diariamente em suas caixas de entrada do e-mail, e que não 
são de seu interesse. Apesar disso, não se pode deixar de reconhecer que as redes sociais e fanpages são ferramentas eficientes.

\subsubsection{PROMOÇÕES DE PRODUTOS}

As promoções de vendas fazem parte do composto de Marketing. Trata-se de uma estratégia utilizada para vender com mais rapidez, oferecendo preços diferenciados ou descontos nos produtos, que se tornam mais atraentes para o público com poder de compra.

Segundo Kotler e Armstrong (2015), existe uma combinação de ferramentas de propaganda que as empresas utilizam para passar aos seus clientes todas as referências e valores de seus produtos e serviços, formando um relacionamento contínuo com seus consumidores.

Senna e Hemais (2017) relatam ser primordial a estratégia de vendas combinadas com os perfis empresariais a quem se estão sendo divulgados, pois favorece a construção de um vínculo com seus clientes, que buscam publicar suas preferências em relação a essas empresas, pelas quais o produto ou serviço foi adquirido, apresentando comentários satisfatórios.

\subsubsection{PLATAFORMAS DE VENDAS ONLINE}

Conhecida como plataforma e-commerce, é um sistema virtual onde as empresas desenvolvem e gerenciam suas lojas, fazendo cadastros de seus produtos para as vendas online.

Conforme Recuero (2019), há diferenças nos conceitos dados aos termos: redes sociais online, digitais e/ou virtuais, e plataformas online, digitais e/ou virtuais. Contudo, estes sempre estão em evolução, sendo importante saber quais as melhorias e o que elas propõem aos consumidores, pois mesmo que as plataformas tenham suas restrições, é bom analisá-las profundamente. 
Segundo D'Andréa (2020), tendo em vista a rapidez com que as redes sociais oferecem produtos e serviços, é necessário verificar a veracidade das fontes, não se deixando influenciar por indicações feitas pelas plataformas mais acessadas, como Facebook, Youtube e Twitter.

\subsubsection{DIVULGAÇÕES DE INFLUENCIADORES DIGITAIS}

O investimento em Influenciadores Digitais por parte das empresas tem como intenção alcançar uma quantidade expressiva de clientes, para que possam não só impulsionar as divulgações da loja, mas também fidelizar novos clientes. Além da internet possuir um alto alcance e velocidade de propagação de informação, nesta é possível encontrar divulgadores que possuem alta influência e números de seguidores. Tal investimento envolve valores muito mais baixos do que aqueles aplicados em meios convencionais como, por exemplo, rádio e tv.

Segundo Felix (2017), as empresas buscam por esses profissionais que divulgam serviços de forma virtual, por terem conhecimento de seu engajamento nas mídias, uma vez que acabam influenciando os seus seguidores a comprarem os produtos ou serviços compartilhados por eles em suas redes sociais.

Silva e Tessarolo (2016) relatam que os seguidores dos influenciadores digitais se espelham neles, e buscam adquirir as mesmas coisas postadas em suas redes sociais para terem um visual parecido e usufruir dos mesmos ambientes que eles.

\subsubsection{W2H}

O 5W2H é uma ferramenta utilizada para definir planos de ações e poder acompanhar a eficiência da empresa, onde constam todas as perguntas relacionadas às questões da organização, com foco no cliente.

Nakagawa (2014) relata que a ferramenta $5 \mathrm{~W} 2 \mathrm{H}$ pode ser utilizada sozinha ou atrelada com outras ferramentas analíticas, podendo ser utilizada em ações que requerem implementações. 
De acordo com Neto (2015), a ferramenta $5 \mathrm{~W} 2 \mathrm{H}$ inicia o projeto com as seguintes perguntas: o quê (what?)? quem (who?)? onde (where?)? quando (when?); porque (why?); como (how?) e quanto (how much?). O quadro onde essas perguntas são anexadas e relacionadas de acordo com as necessidades encontradas na empresa, permite ao projetista ter uma ampla ideia em relação ao projeto. Por meio do qual é possível discutir todos os problemas, viabilizar as variáveis dos problemas, organizar e estudar os stakeholders, e definir as variáveis do problema para o projeto.

\section{MATERIAIS E MÉTODOS}

Materiais e métodos dizem respeito a um planejamento de todo o desenvolvimento do estudo, detalhado de forma concisa e clara, para maior compreensão dos leitores.

Conforme Xavier et al. (2017), utiliza-se de diversos modelos, com o objetivo de facilitar o entendimento e poder expor toda a complexidade do processo.

Markus et al. (2017) apontam que os materiais e métodos são análises relevantes à tomada de decisão, por possibilitar melhorias e dar suporte ao estudo de caso da pesquisa, permitindo encontrar uma solução efetiva para o problema encontrado.

\subsection{PROCEDIMENTOS METODOLÓGICOS}

O procedimento metodológico consiste em tomadas de decisões e ações, relacionadas à escolha dos métodos e das técnicas a serem utilizadas para o desenvolvimento de um trabalho científico.

Fonseca (2017) expõe que a metodologia do artigo se baseia na pesquisa de campo e coleta de dados, assim como, nas informações documentais, sendo essa a primeira etapa a ser desenvolvida na pesquisa. 
No conceito de Vasconcelos (2014), os procedimentos metodológicos decorreram da frequência utilizada nos trabalhos revisados, a partir das demandas de natureza técnica.

Este estudo se ancorou em uma pesquisa bibliográfica, de campo e documental, por meio de uma abordagem quanti-qualitativa. Como coleta de dados, foi realizada uma entrevista com a gerente da empresa, onde foram feitas perguntas abertas e fechadas com o objetivo de aproximar-se da realidade investigada, sendo também analisadas planilhas e documentos da empresa.

\subsubsection{QUANTO À NATUREZA}

Foi utilizada a pesquisa aplicada, qualitativa e quantitativa, com objetivo de solucionar o problema específico da empresa, fazendo-se uso de informações, gráficos e tabelas. A pesquisa destina-se a avaliar melhor a empresa.

Conforme Oliveira et al. (2018), esta se caracterizou como uma pesquisa aplicada, pois gerou conhecimentos e objetivos que permitiram solucionar o problema específico.

De acordo com Ensslin et al. (2013), o conhecimento geral da pesquisa se dá através dos processos de análise e escolha de artigos, obedecendo os requisitos dos pesquisadores.

\subsubsection{QUANTO AOS FINS}

$\mathrm{Na}$ Chilli Beans formalizou-se um breve levantamento de dados com a gerente, onde foi feita uma entrevista, que com questões objetivas, evidenciou um problema na área de Marketing da empresa. Contudo, através desta entrevista, viabilizou-se a solução adequada com a busca de meios de divulgação eficazes. 
Segundo Furtado (2014), a entrevista deve suceder de maneira franca do começo ao fim, caso o pesquisador tenha que voltar a conversar com o entrevistado para um eventual retorno.

Conforme Figueira et al. (2013), a pesquisa descritiva investiga relatórios contábeis, demonstrando as características contábeis das empresas.

\subsubsection{QUANTO AOS MEIOS}

$\mathrm{Na}$ entrevista com a gerente da empresa LTRG Comércio Varejista de Óculos e Relógios Ltda, realizou-se um levantamento financeiro e uma análise referente a área funcional de marketing.

Segundo Salgado (2016), uma pesquisa pode ser realizada através de um questionário já utilizado para solução de problemas no meio acadêmico.

$\mathrm{Na}$ concepção de Oliveira et al. (2018), quanto aos meios, esta pesquisa é conceituada como uma pesquisa qualitativa com coleta de materiais, pois possui vínculo com as informações a serem levantadas, para tomada de decisão da empresa.

\subsection{CARACTERÍSTICAS DA EMPRESA}

A empresa LTRG Comércio Varejista de Óculos e Relógios Ltda (Loja franqueada), foi fundada em 1997, na administração do Sr. Antônio Caio Gomes Pereira Filho (Caito Maia). Inicialmente esta teve poucos recursos para dar início em uma feira popular de São Paulo conhecida como Mercado Mundo Mix, com vendas de alguns produtos relacionados a seus negócios.

Apesar de começar com alguns produtos que restaram de sua empresa que veio a falência, a Blue Velvet; teve sua primeira loja inaugurada no shopping center em 2000, que se expandiu rapidamente, lançando conceitos self-service, eliminando as 
vitrines e vidros, e expondo seus produtos com um arranjo bem chamativo ao público.

Hoje tem uma marca bem-posicionada no mercado, com mais de 600 pontos de franquias pelo Brasil e 40 unidades fora do Brasil, sempre com vendas acima de 1.6 milhões anualmente, com mais de 50 fabricantes, também licenciando sua marca para outros segmentos voltado ao público jovem, mas podendo ser adquirida para outras faixas etárias.

Nesse contexto, a franquia que esteve representada neste estudo de caso está localizada em Manaus, na Avenida Eduardo Ribeiro, $n^{\circ} 620$, no Centro da cidade Zona Sul. Tem a finalidade de trazer resultados satisfatórios para seus clientes, levando em conta os desejos de seus consumidores, buscando fidelizá-los, e focando sempre em inovações dos seus produtos e serviços. Sendo assim, seus colaboradores têm treinamento constante para um atendimento diferenciado, com o foco em alcançar uma qualidade superior em seu atendimento e aumentar o caráter da marca no mercado competitivo.

\section{RESULTADOS E DISCUSSÕES}

O diagnóstico organizacional foi realizado a partir de entrevistas e visitas de campo na empresa Ltrg Comércio Varejista de Óculos e Relógios Ltda. Neste foi possível observar o desempenho das áreas funcionais da empresa, conforme o representado no gráfico 01. 
Gráfico 01: Média - Desempenho por área funcional

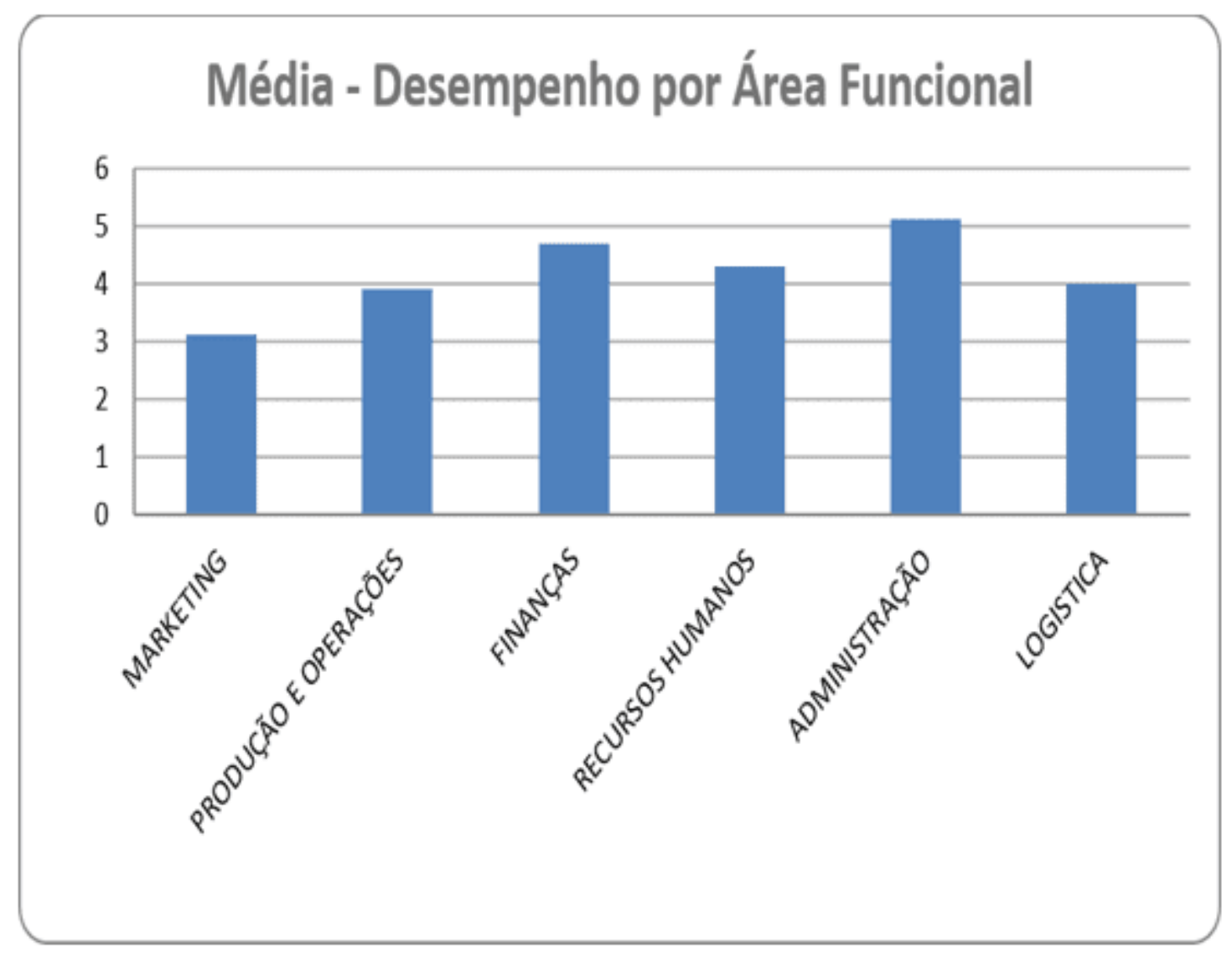

Fonte: Elaborado pelos autores, 2021.

Observando o gráfico 01, é possível visualizar que as áreas de administração e de finanças têm os melhores desempenho na empresa; as áreas de recursos humanos, logística, produção e operações possuem médio desempenho. Identificando, portanto, o marketing como a área mais crítica da empresa.

Quadro 01: Marketing

\begin{tabular}{|l|l|l|l|l|l|}
\hline MARKETING & PONTO & PONTO & PONTO & PONTO & PONTO \\
& MUITO & FORTE & MÉDIO & FRACO & MUITO \\
\hline FORTE & 4 & 3 & 2 & FRACO \\
\hline 5 & & & & 1 \\
\hline
\end{tabular}

RC: 101965

Disponível em: https://www.nucleodoconhecimento.com.br/administracao/mercadocomo-referencia 


\begin{tabular}{|c|c|c|c|c|c|c|}
\hline 1 & $\begin{array}{l}\text { Satisfação dos serviços } \\
\text { reconhecida pelo mercado e } \\
\text { clientes. }\end{array}$ & & & $\mathrm{X}$ & & \\
\hline 2 & $\begin{array}{l}\text { Seus produtos são } \\
\text { especificados e excelentes }\end{array}$ & & $\mathrm{X}$ & & & \\
\hline 3 & Variedades de serviços. & & & $\mathrm{X}$ & & \\
\hline 4 & $\begin{array}{l}\text { A empresa possui ótimas } \\
\text { estratégias de preços. }\end{array}$ & & $\mathrm{X}$ & & & \\
\hline 5 & $\begin{array}{l}\text { O local onde a empresa se } \\
\text { encontra favorece a melhoria } \\
\text { de vendas. }\end{array}$ & & & & $\mathrm{x}$ & \\
\hline 6 & $\begin{array}{l}\text { A organização tem manobras } \\
\text { de comunicação audiovisual. }\end{array}$ & & & $\mathrm{x}$ & & \\
\hline 7 & $\begin{array}{l}\text { A organização estabelece } \\
\text { uma apresentação inovadora } \\
\text { de seus produtos e serviços. }\end{array}$ & & & $\mathrm{x}$ & & \\
\hline \multicolumn{2}{|c|}{$\operatorname{TOTAL}(\Sigma)$} & 0 & 8 & 21 & 2 & 0 \\
\hline \multicolumn{2}{|r|}{$\begin{array}{l}\text { DESEMPENHO DA ÁREA } \\
\text { TOTAL }\end{array}$} & \multicolumn{5}{|l|}{3.1} \\
\hline \multicolumn{2}{|r|}{ ÁREA FUNCIONAL } & \multicolumn{5}{|c|}{ NÍVEL OU GRAU DE AVALIAÇÃO } \\
\hline
\end{tabular}

Fonte: Elaborado pela equipe, 2021.

Observando o quadro 01, o marketing da empresa apresenta como ponto de desempenho médio: a satisfação dos desejos dos clientes e a padronização e variedades dos produtos e serviços. Tendo como ponto crítico a localização da franquia, que não favorece nas vendas dos produtos.

Logo, este artigo possui como pergunta problema: como melhorar a visibilidade da marca por meio de estratégias de divulgação da empresa em todas as faixas de poder aquisitivo? 


\subsection{PLANEJAMENTO DE AÇÕES}

O planejamento de ações consiste em um método aplicado que é determinante para se alcançar os objetivos estabelecidos na pesquisa científica. Para que o pesquisador chegue à meta estabelecida, é fundamental utilizar gráficos para descrever as atividades que devem ser executadas por cada setor, a fim de poder acompanhar todas áreas e etapas da conclusão do plano a ser realizado.

Quadro 02: Ações interventivas

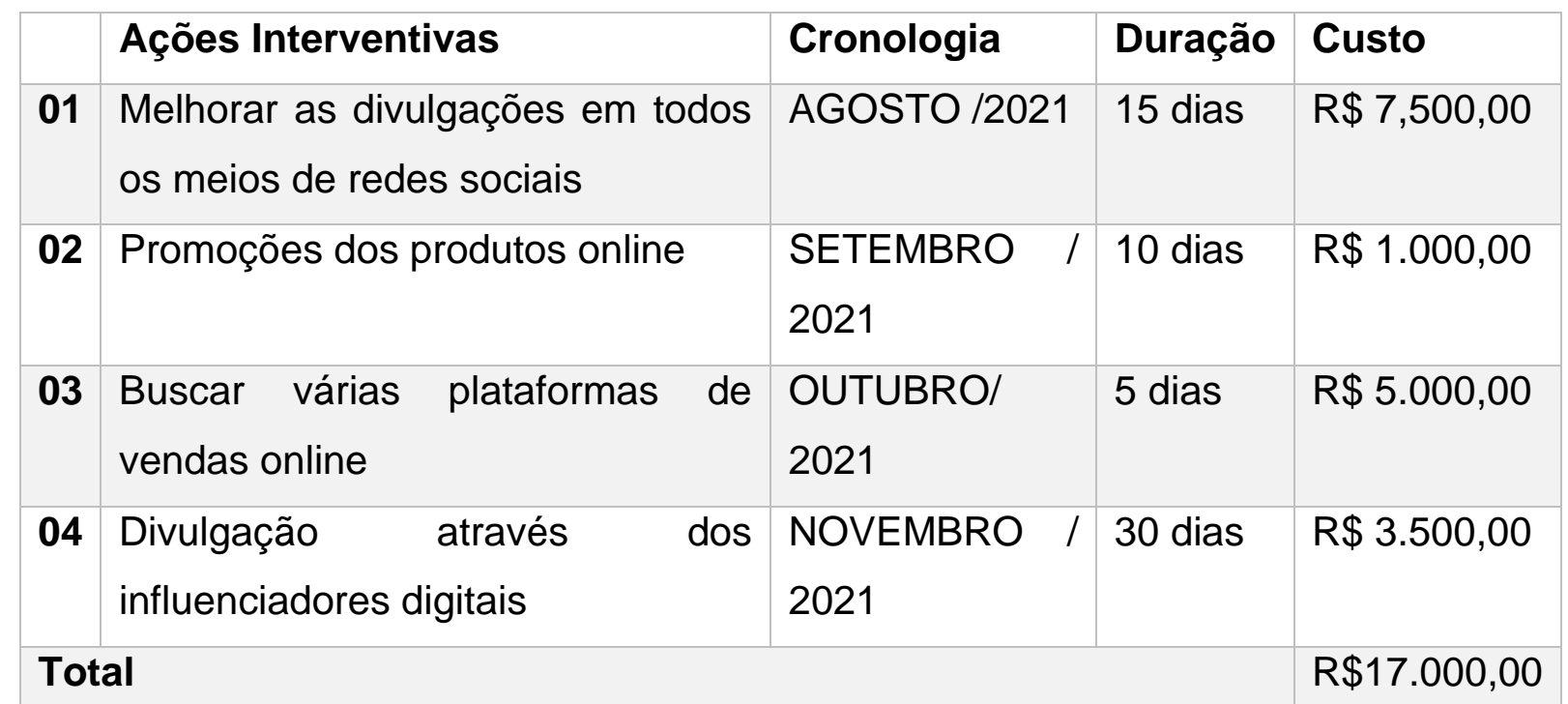

Fonte: Elaborado pelos autores, 2021.

Destaca-se no quadro 2, quatro propostas de ações interventivas, a fim de solucionar os problemas da empresa, de forma prática e eficiente, e melhorar as suas divulgações em todas as redes sociais.

\subsubsection{DIVULGAÇÃO NAS REDES SOCIAIS}

Estabeleceram-se, em comum acordo com os gestores, novos meios de divulgação, com o propósito de obter mais engajamento nas redes sociais e alcançar mais clientes. 
Quadro 03: 5W2H - Melhorar as divulgações em todos os meios de rede social

Melhorar as divulgações em todos os meios de rede social

O que? Divulgação nas redes sociais.

Por quê? Para alcançar mais clientes de maneira mais rápida.

Onde? Na loja LTRG Comércio Varejista de Óculos e Relógio Ltda.

Quando? Primeira semana de agosto de 2021.

Quem? Os colaboradores que atuam no atendimento online.

Como? Por meio dos colaboradores que divulgam e tem total interação com os clientes.

Quanto? $\mathrm{R} \$ 7.500,00$

Fonte: Elaborado pelos autores, 2021.

Como mostra o quadro 03, a divulgação é necessária para loja LTRG Comércio Varejista de Óculos e Relógio Ltda, por meio da atuação e interação dos colaboradores com os clientes, para alcançar mais clientes de forma rápida através das mídias sociais. Com um gasto de $\mathrm{R} \$ 7.500,00$ para a implementação das divulgações nas redes sociais, e com data inicial para a primeira semana de agosto de 2021.

Espera-se que, com as divulgações nas redes sociais e o esforço dos colaboradores, a empresa obtenha maior engajamento nas mídias sociais e alcance mais clientes em todas as faixas de poder aquisitivo.

\subsubsection{PROMOÇÕES DOS PRODUTOS ONLINE}

Estabelece-se vendas através de meios virtuais, com preços acessíveis e ofertas para atrair a atenção dos clientes, e tornar os clientes fiéis ao produto através das promoções online. 
Quadro 04: 5W2H - Promoções dos produtos online

Promoções dos produtos online.

O que? Promoções de produtos

Por quê? Para que os clientes de diferentes poderes aquisitivos possam adquirir o produto.

Onde? LTRG Comércio Varejista de Óculos e Relógio Ltda.

Quando? Primeira semana de setembro de 2021.

Quem? Os gestores da loja.

Como? Avaliar o estoque para atender as promoções, e estabelecer os valores a ser vendido.

Quanto? R\$1.000,00

Fonte: Elaborado pelos autores, 2021.

Considera-se no quadro 04, promoções de produtos com o propósito de alcançar clientes com poderes aquisitivos diferenciados, sob um valor de $R \$ 1.000,00$ a ser gasto para os custos necessários à implementação, com data inicial para a primeira semana de setembro de 2021.

Com a publicidade, espera-se satisfazer as necessidades da loja em ter mais clientes, e poder vender estes produtos com preços acessíveis a todas as faixas, aumentando a visibilidade e a demanda da loja.

\subsubsection{BUSCAR PLATAFORMAS DE VENDAS ONLINE}

Com essa proposta, objetiva-se encontrar diferentes plataformas que sejam coerentes para o engajamento contínuo da imagem da marca nas mídias sociais.

Quadro 05: 5W2H - Buscar várias plataformas de vendas online

Buscar várias plataformas de vendas online

O que? Buscar plataformas de vendas. 
Por quê? Para vender produtos em plataformas diferentes da marca.

Onde? LTRG Comércio Varejista de Óculos e Relógio Ltda.

Quando? Primeira semana de outubro de 2021.

Quem? Os colaboradores que atuam na área de Marketing.

Como? Os colaboradores buscam plataformas diferentes da marca, para poder associar seus produtos com a plataforma encontrada.

Quanto? $\mathrm{R} \$ 5.000,00$

Fonte: Elaborado pelos autores, 2021.

Observa-se que no 05, os colaboradores devem procurar por diferentes plataformas, a fim de se alcançar novos clientes. Para a implementação dessa proposta haverá um gasto de $R \$ 5.000,00$, com data de início prevista para a primeira semana de outubro de 2021.

Espera-se que, com a busca de novas plataformas, ocorra a entrada de novos clientes à procura de produtos e serviços da empresa, visando o aumento da demanda e satisfação dos mesmos.

\subsubsection{DIVULGAÇÃO ATRAVÉS DOS INFLUENCIADORES DIGITAIS}

Adotou-se a contratação dos influenciadores digitais para implementação da marca Chilli Beans, com ajuda de sua forte influência nas mídias sociais.

Quadro 06: 5W2H - Divulgação através dos influenciadores digitais

Divulgação através dos influenciadores digitais.

O que? Divulgações de influenciadores digitais.

Por quê? Para que possa se utilizar de suas fortes influências.

Onde? LTRG Comércio Varejista de Óculos e Relógio Ltda.

Quando? Primeira semana de novembro de 2021.

Quem? Os gestores são os que conduzem a contratação dos profissionais 
correspondentes a influenciadores.

Como? Os influenciadores incentivam os clientes a conhecer a marca Chilli Beans.

Quanto? R\$3.500,00.

Fonte: Elaborado pelos autores, 2021.

Elencaram-se os influenciadores digitais com o propósito de alcançar novos clientes para a empresa em estudo, aumentando sua forma de alcançar compradores e sua demanda de produtos. Com data inicial para a primeira semana de novembro de 2021, com valor de $R \$ 3.500,00$ a ser implementado no serviço de divulgação de influenciadores digitais.

Com o engajamento nas redes sociais dos influenciadores para divulgação da marca, espera-se reconhecimento por parte dos clientes.

\subsection{FLUXOGRAMA DA MELHORIA PROPOSTA}

Analisaram-se os dados da área de Marketing, a partir do qual foi elaborado um fluxograma para a empresa Chilli Beans. Destaca-se a melhoria da divulgação da marca nas redes sociais, visando aumentar não somente a demanda, mas a clientela da loja. 
Imagem 01: Fluxograma da melhoria proposta

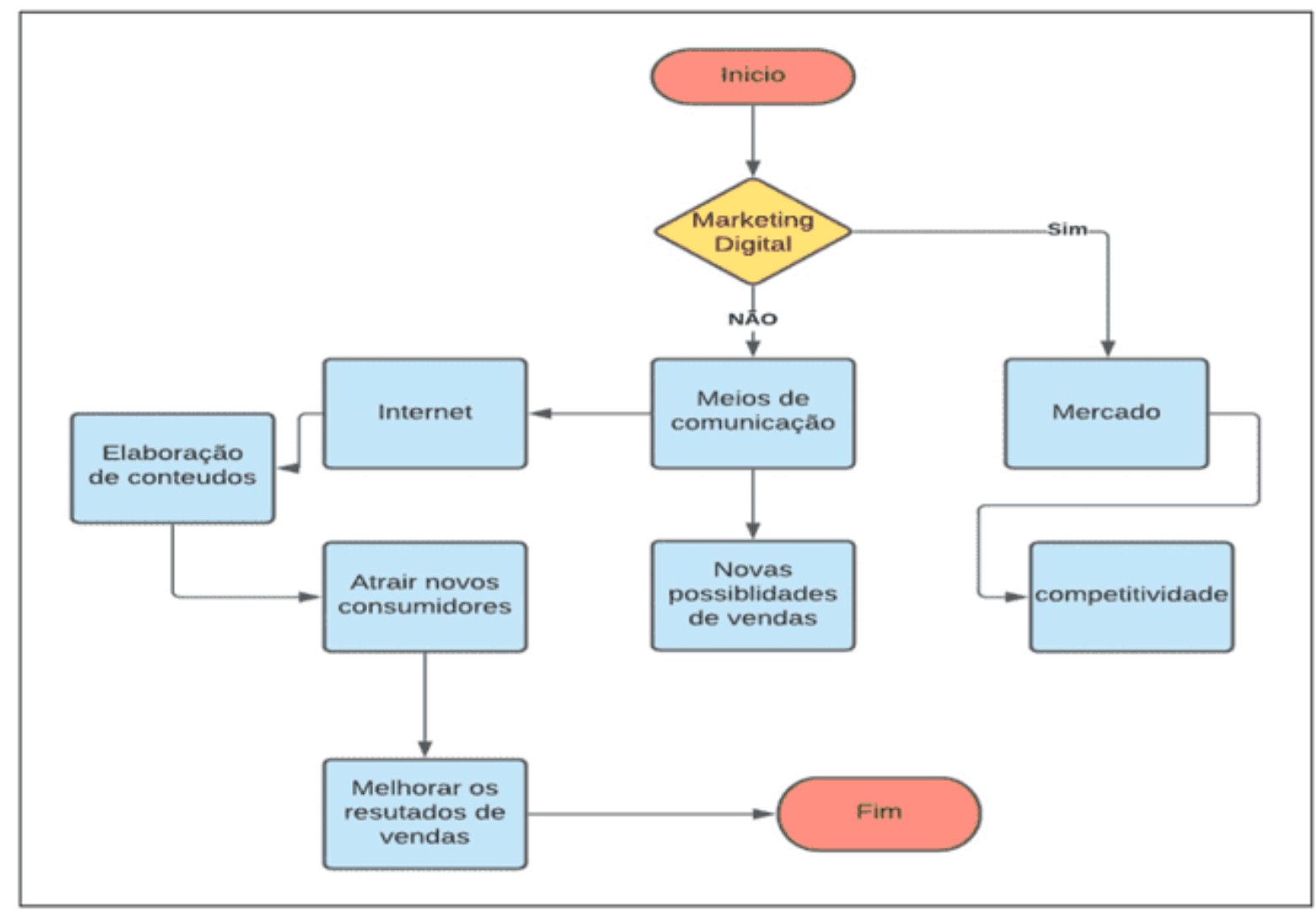

Fonte: Elaborado pelos autores, 2021.

Baseado na imagem 01, constatou-se que a área de Marketing da empresa Chilli Beans se inovou na aplicação de meios de divulgações como: contratações de influenciadores digitais; e uso de várias plataformas, alcançando seu objetivo, tornando-se ainda mais competitiva e obtendo resultados satisfatórios em suas vendas.

\section{CONSIDERAÇÕES FINAIS}

Com as mudanças de mercado e a concorrência cada vez mais acirrada, as organizações estão em constante mudança e aprimoramento. Neste sentido, este artigo procurou desenvolver procedimentos específicos para a organização estudada, apresentando uma oportunidade de melhoria para a problemática central da empresa, evidenciada por análises mercadológicas e organizacionais. Assim, 
com a implementação das medidas, observou-se resultados satisfatórios frente à realidade presenciada.

A respeito da pergunta norteadora deste estudo de caso: como melhorar a visibilidade da marca por meio de estratégias de divulgação da empresa em todas as faixas de poder aquisitivo? O estudo permitiu que se estabelecesse um conjunto de ações com o propósito de melhorar as divulgações em todos os meios de redes sociais; promover produtos online; buscar atuação em várias plataformas de vendas online; e propor a divulgação por meio dos influenciadores digitais; visando a reestruturação das formas de divulgação da marca para a atualização de técnicas de marketing voltada ao novo modelo de gestão de público-alvo nos meios virtuais. De forma geral, os serviços da LTRG Comércio Varejista de Óculos e Relógio Ltda apresentaram resultados positivos nas áreas estudadas neste artigo.

Sendo assim, para a realização desta pesquisa, primeiramente realizou-se a coleta de dados por meio de visitas técnicas e entrevistas com os funcionários e a gestão primária, para uma análise das condições. Após isso, foram feitos alguns levantamentos dessas análises, em forma de gráficos e tabelas.

Este artigo realizou um estudo de caso na empresa LTRG Comércio Varejista de Óculos e Relógio Ltda, a partir da análise de informações com o foco nas condições de serviço de divulgação da empresa, visando como a comercialização e divulgação dos seus produtos podem ser desenvolvidos para melhorar o vínculo com os seus clientes.

Com base nos dados coletados, ficou evidente que, apesar de a empresa ter determinado reconhecimento mercadológico no seu campo de atuação, a mesma carecia de estratégias efetivas de marketing com atuações que pudessem atingir vários públicos, principalmente no que se refere à precificação correspondentes aos consumidores das mais variadas classes econômicas.

Contudo, ressalta-se que para a efetividade das estratégias que envolvem a precificação, se faz necessário desenvolver medidas de divulgação da marca na sua 
área de atuação, para que assim possa ser transmitido certa segurança aos potenciais clientes, levando esses a apostarem na marca, mesmo considerando uma quantidade significativa de concorrentes.

Logo, se destaca a importância de se manter atualizado em relação às formas de divulgação dos produtos com um mix variado, englobando várias faixas de clientes. Ressalta-se a necessidade de se estar a par das tendências e mudanças do mercado atual.

Por fim, o trabalho possibilitou verificar que as mudanças feitas através de ferramentas e colaboradores (engajamento, divulgações e novas contratações de tecnologias e funcionários) promoveram o resultado esperado, que era o aumento da visibilidade da marca e, consequentemente, o aumento de novos clientes. Observou-se ainda o reconhecimento da localização da franquia, devido ao compartilhamento por parte dos clientes que passaram a divulgar a localização da loja.

Ressalta-se ainda, que com a maior visibilidade da marca a empresa preocupou-se em atender aos diferentes públicos, com maior e menor poder aquisitivo. Isto foi possível, por conta das ações de marketing e promoções realizadas, a fim de possibilitar o acesso aos produtos pelos mais variados clientes.

Destaca-se que este trabalho não possui a pretensão de responder a todas as dificuldades encontradas no decorrer do estudo, mas preocupou-se em responder, ainda que parcialmente, ao questionamento realizado no momento inicial deste estudo. Logo, a pesquisa é um processo contínuo que ao ser realizada, possibilita a abertura de novos caminhos para o desenvolvimento de novos estudos.

\section{REFERÊNCIAS}

D'ANDRÉA, C. Para além dos "dados coletados": políticas das APIs e mediações algorítmicas nas plataformas de mídia social. In: COMPÓS, Campo Grande. COMPÓS, 2020.

RC: 101965

Disponível em: https://www.nucleodoconhecimento.com.br/administracao/mercadocomo-referencia 
ENSSLIN, S. R. et al. Evidenciação do estado da arte do tema avaliação do desempenho na regulação de serviços públicos segundo a percepção dos pesquisadores. Revista Gestão Pública: Práticas e Desafios, Recife, v. IV, n. 7, ago. 2013.

FELIX, E. C. O Papel Dos Influenciadores Digitais No Processo De Decisão De Compra. Universidade Federal do Rio Grande do Norte, Natal, 2017.

FIGUEIRA, L. M. et al. CPC 29: Uma Análise dos Requisitos de Divulgação entre Empresa de Capital Aberto e Fechado do Setor de Agronegócios. Sociedade, Contabilidade e Gestão, Rio de Janeiro, v. 8, n. 1, 2013.

FONSECA, R. C. V. Metodologia do trabalho científico. Curitiba: IESDE, 2017.

FURTADO, M. S. V. Trabalho de Conclusão (TCC) em Ciências Políticas Aplicadas/Maria Sueli Viana Furtado, Simone Viana Duarte. São Paulo: Saraiva, 2014.

KOHN, I. V.; ELIAS, V. M. Ler e compreender: os sentidos do texto. 3. ed. Contexto: São Paulo, 2014.

KOTLER, P.; ARMStRONG, G. Princípios de Marketing. 15. ed. São Paulo: Pearson Education do Brasil, 2015.

MARKUS, L. A. et al. Atuação do enfermeiro na assistência ao paciente em cuidados paliativos. Revista Gestão \& Saúde, RGS, 2017.

NAKAGAWA, M. Ferramenta 5W2H: plano de Ação para Empreendedores. Globo, 2014.

NETO, A. Metodologia Laila: guia de etapas e ferramentas para a concepção de projetos centrados no ser humano. Campos do Goytacazes, 2015. 
OLIVEIRA, F. R. de. et al. Horta Escolar, Educação Ambiental e a Interdisciplinaridade. Revbea, São Paulo, V. 13, № 2: 10-31, 2018.

RECUERO, R. Mídia social, plataforma digital, site de rede social ou rede social? Não é tudo a mesma coisa? Medium, 2019. Disponível em: https://medium.com/@raquelrecuero/m\%C3\%ADdia-social-plataforma-digital-site-derede-social-ou-rede-social-n\%C3\%A3o-\%C3\%A9-tudo-a-mesma-coisad7b54591a9ec. Acesso em: 01 de out. de 2021.

ROCHA, T. V. et al. Estudo Exploratório sobre o uso das Redes Sociais na Construção do Relacionamento com Clientes. Revista Brasileira de Gestão de Negócios, São Paulo, v. 15, n. 47, p.262-282, abr. 2013.

SALGADO, W. F. Qualidade de vida no trabalho em empresa automotiva: comparação entre área administrativa e de produção. Universidade Estadual Paulista. Guaratinguetá, 2016.

SENNA, S. S.; HEMAIS, M. W. Significados Associados a Shopping Centers por Consumidores da Classe C. Revista de Administração da UNIMEP, v. 15, n. 4, p. 93-116, 2017.

SGANZERLLA, S. Marketing de relacionamento. São Paulo: Anhembi Morumbi, 2013.

SILVA, C. R. M.; TESSAROLO, F. M. Influenciadores digitais e as redes sociais enquanto plataformas de mídias. XXXIX Intercom, São Paulo, 2016.

SILVA, L. A. da. Administração de Marketing. Universidade Estácio de Sá, Rio de Janeiro, 1. ed., 2015.

VALLE, A. Marketing Digital para pequenas empresas. Alberto Valle, 2014. Disponível em: http://www.albertovalle.com.br/marketing-digital- para- pequenasempresas/. Acesso em: 01 de out. de 2021. 
VASCONCELOS, Y. L. Estudos Bibliométricos: Procedimentos Metodológicos e Contribuições. UNOPAR Cient., Ciênc. Juríd. Empres., Londrina, v. 15, n. 2, p. 211 220, 2014.

XAVIER, C. et al. Gerenciamento de projetos de mapeamento e redesenho de processos: uma adaptação da metodologia basic methodware. Rio de janeiro: Brasport livros e multimídia, 2017.

Enviado: Outubro, 2021.

Aprovado: Novembro, 2021. 